\title{
Carbon-ion Radiotherapy for Oligometastatic Colorectal Cancer in the Liver or Lung
}

\author{
SHINTARO SHIBA $^{1,2}$, KEI SHIBUYA ${ }^{1}$, MASAHIKO OKAMOTO ${ }^{1}$, NAOKO OKANO $^{2}$, \\ NOBUTERU KUBO ${ }^{1}$, TAKUYA KAMINUMA ${ }^{1}$, HIRO SATO ${ }^{1}$, SHOHEI OKAZAKI ${ }^{2}$, \\ YUHEI MIYASAKA ${ }^{2}$, HIDEMASA KAWAMURA ${ }^{2}$ and TATSUYA OHNO ${ }^{1}$ \\ ${ }^{1}$ Department of Radiation Oncology, Gunma University Graduate School of Medicine, Gunma, Japan; \\ ${ }^{2}$ Gunma University Heavy Ion Medical Center, Gunma, Japan
}

\begin{abstract}
Background/Aim: We aimed to evaluate the clinical outcomes of oligometastatic colorectal cancer in the liver and lung treated with carbon-ion radiotherapy $(C$-ion $R T)$. Patients and Methods: Nineteen consecutive patients with oligometastatic colorectal cancer in the liver or lung who received $C$-ion $R T$ were analyzed. The doses of $C$-ion $R T$ were $60.0 \mathrm{~Gy}$ [relative biological effectiveness (RBE)] in 4 fractions, $60.0 \mathrm{~Gy}(\mathrm{RBE})$ in 12 fractions, or 64.8 Gy (BRE) in 12 fractions. Results: The median follow-up duration was 19 months. There were 23 tumors in 19 patients. The 2-year overall survival and local control rates for the whole patient cohort were $100 \%$ and $67 \%$, respectively. None of the patients developed grade 2 or higher acute or late toxicities. Conclusion: $C$-ion $R T$ for oligometastatic colorectal cancer in liver and lung provides favorable clinical outcomes. These outcomes suggest $C$-ion $R T$ is a treatment option for oligometastatic colorectal cancer in liver and lung.
\end{abstract}

Oligometastatic disease is an intermediate state between localization and widespread dissemination (1). Therefore, controlling oligometastatic disease by local treatment may improve survival. Colorectal cancer is one of the cancer types that are characterized by oligometastases of the liver and lung. Local treatment of oligometastatic colorectal cancer, with or without chemotherapy, is performed to improve survival (27). In contrast, radiotherapy (RT) is performed as a local treatment approach for patients who are not indicated for surgery due to comorbidity or refusal of surgery (8-15).

This article is freely accessible online.

Correspondence to: Shintaro Shiba, Department of Radiation Oncology, Gunma University Graduate School of Medicine, 3-3922, Showa-machi, Maebashi, Gunma 371-8511, Japan. Tel.: +81 272208383, Fax: +81 272208397, e-mail: shiba4885@yahoo.co.jp

Key Words: Carbon-ion radiotherapy, oligometastases, colorectal cancer, liver metastases, lung metastases.
Carbon-ion (C-ion) RT is performed to treat various types of cancer, including hepatocellular carcinoma, lung cancer, and oligometastatic disease (16-21). C-ion RT has biological and physical advantages over photon therapy. Owing to its biological properties, C-ion RT has a higher relative biological effectiveness (RBE) due to the high linear energy transfer in the Bragg peak. Furthermore, its physical properties allow administration of high doses while sparing normal tissues because of its higher dose localization ability with distal tail-off enabled by the Bragg peak and sharp lateral penumbra (22). Previous studies have demonstrated a dose distribution advantage, showing that C-ion RT delivered a reduced dose to the normal liver and lung compared with stereotactic body RT (SBRT) and intensity-modulated RT (23-25). The biological and physical advantages may contribute to favorable clinical outcomes. However, research on the clinical outcomes of oligometastatic colorectal cancer treated with C-ion RT is limited. Hence, we aimed to evaluate the clinical outcomes of oligometastatic colorectal cancer in the liver and lung treated with C-ion RT.

\section{Patients and Methods}

Patients. We reviewed the medical records of patients with oligometastatic colorectal cancer in the liver or lung treated with Cion RT at Gunma University Heavy Ion Medical Center between October 2013 and March 2020. We enrolled 19 consecutive patients who met the following criteria: i) Liver or lung metastases from colorectal cancer as confirmed by histology or radiography; ii) curative resection for primary disease and regional lymph nodes, without gross or microscopic residual disease; iii) absence of local primary colorectal lesion and lymph node recurrence; iv) absence or control of extrahepatic or extra-thoracic disease; v) $\leq 3$ synchronous liver or lung metastases at the time of treatment; vi) not indicated or refused surgery for metastatic disease of liver or lung ; vii) radiographically measurable tumor; and viii) performance status $\leq 3$ by the Eastern Cooperative Oncology Group classification. Cases were excluded if they had received prior RT to the target area, had intractable infections in the target area, or had received chemotherapy/molecular targeted therapy within 4 weeks before the 
initiation of C-ion RT. The treatment protocol was reviewed and approved by the Gunma University Institutional Review Board (approval number: HS2019-130), and all patients signed an informed consent form before the initiation of therapy.

Carbon-ion radiotherapy. A heavy ion accelerator at Gunma University Heavy Ion Medical Center generated C-ion beams, and the beam energy was either $290 \mathrm{MeV} / \mathrm{u}, 380 \mathrm{MeV} / \mathrm{u}$, or $400 \mathrm{MeV} / \mathrm{u}$ according to the tumor depth. The XiO-N system (version 4.47; collaborated product of Elekta AB, Stockholm, Sweden, and Mitsubishi Electric, Tokyo, Japan) was used for treatment planning. This system incorporates a dosing engine for ion beam RT (K2dose) (25). We calculated the clinical radiation dose based on the physical dose multiplied by the RBE of the $\mathrm{C}$-ions. Before $\mathrm{C}$-ion RT, patients were immobilized using tailor-made fixation cushions and thermoplastic shells to allow computed tomography $(\mathrm{CT})$; respiratorygated and 4-dimensional CT images were acquired. In actual treatment, the gating level for respiratory-gated irradiation was within $30 \%$ of the wave height around the peak exhalation. Patients received C-ion RT once daily, 4 days a week (Tuesday to Friday).

The gross tumor volume (GTV) was delineated by the treatment planning CT images, which were merged with the contrast-enhanced CT images, contrast-enhanced magnetic resonance imaging (MRI), with/without 2-deoxy-2-[ $\left.{ }^{18} \mathrm{~F}\right]$ fluoro-D-glucose (FDG)-positronemission tomography (PET)/CT images if necessary. The clinical target volume had 5-10 $\mathrm{mm}$ margin around the GTV to include microscopic disease. The internal margin was assessed using 4dimensional CT images for tumor movement. The planning target volume was defined as the summation of the clinical target volume, internal margin, and setup margin. The prescribed doses were $60 \mathrm{~Gy}$ (RBE) in four fractions for cases with peripheral metastatic tumor, 60 Gy (RBE) in 12 fractions for cases with metastatic tumor close to the gastrointestinal tract, and $64.8 \mathrm{~Gy}(\mathrm{RBE})$ in 12 fractions for cases with large metastatic tumor $(>5 \mathrm{~cm})$. The treatment aim was to cover $95 \%$ of the PTV with at least $95 \%$ of the prescribed dose. The dose constraints were as follows: Dose to $1 \mathrm{~cm}^{3}\left(\mathrm{D}_{1 \mathrm{cc}}\right)<40 \mathrm{~Gy}$ (RBE) administered to the gastrointestinal tract in standard cases; $\mathrm{D}_{1 \mathrm{cc}}<45 \mathrm{~Gy}$ (RBE) administered to the gastrointestinal tract in the cases treated with 12 fractions; organ volume that received at least $10 \%$ of the administered dose $\left(\mathrm{V}_{10}\right)<55 \%$ and $\mathrm{V}_{20}<40 \%$ administered to the liver; $\mathrm{V}_{20}<20 \%$ administered to the lung; maximum dose $\left(\mathrm{D}_{\max }\right)<30 \mathrm{~Gy}(\mathrm{RBE})$ administered to the spinal cord; $\mathrm{D}_{\max }<52.8 \mathrm{~Gy}$ (RBE) administered outside the PTV at the porta hepatis (including the first branch of the portal vein and hepatic duct); $\mathrm{D}_{\max }<45 \mathrm{~Gy}$ (RBE) administered to the skin in standard cases; and $\mathrm{D}_{\max }<50 \mathrm{~Gy}$ (RBE) administered to the skin in the cases treated with 12 fractions. Figures 1 and 2 show radiographical images before $\mathrm{C}$-ion $\mathrm{RT}$ and typical clinical dose distribution with $\mathrm{C}$-ion $\mathrm{RT}$ of patients with oligometastatic colorectal cancer in the liver and lung.

Evaluation during follow-up. Patients were followed-up for 1 month after the completion of C-ion RT and every 3 months thereafter. Follow-up examinations comprised routine testing of blood cell counts and chemistry and diagnostic imaging using CT, MRI, or FDG-PET. Acute and late toxicities were graded according to the Common Terminology Criteria for Adverse Events (version 4.0) of the National Cancer Institute (27). Acute and late toxicities were evaluated as the highest grade of toxicity that occurred within 3 months and after 3 months of initiating $\mathrm{C}$-ion RT, respectively.
Dose-volume histogram analysis. Dose-volume histogram (DVH) analysis was used to evaluate the dose of C-ion RT to normal liver and normal lung (i.e. total liver or lung volume minus GTV). We assessed the mean liver or lung dose, and the percentage of the normal liver or lung that received at least 5, 10, 15, 20, 25, 30, 40, and 50 Gy $(\mathrm{RBE})\left(\mathrm{V}_{5}, \mathrm{~V}_{10}, \mathrm{~V}_{15}, \mathrm{~V}_{20}, \mathrm{~V}_{25}, \mathrm{~V}_{30}, \mathrm{~V}_{40}\right.$, and $\left.\mathrm{V}_{50}\right)$ based on the DVH.

Statistical analysis. All statistical analyses were performed using the Statistical Package for the Social Sciences software (version 25.0; IBM Inc., Armonk, NY, USA). Survival was measured from the date of $\mathrm{C}$-ion $\mathrm{RT}$ initiation to death or the most recent followup. Local control (LC) was defined as no evidence of local recurrence without an increase in tumor size on CT or MRI and no increase in FDG uptake on PET. Progression-free survival (PFS) was defined as the absence of progression of both local and distant metastases. PFS was measured from the date of initiation of C-ion RT to the date of tumor progression or death from any cause. The probabilities of overall survival (OS), LC, and PFS rates were calculated using the Kaplan-Meier method. Next, we evaluated the potential prognostic effect of sex (male or female), age ( $<65$ or $\geq 65$ years), performance score ( 0 or 1 ), primary tumor site (rectum or colon), tumor location (liver or lung), tumor size ( $<3$ or $\geq 3 \mathrm{~cm})$, GTV volume $\left(<10 \mathrm{~cm}^{3}\right.$ or $\left.\geq 10 \mathrm{~cm}^{3}\right)$, clinical target volume $\left(<40\right.$ or $\left.\geq 40 \mathrm{~cm}^{3}\right)$, serum carcinoembryonic antigen level $(<5.0$ or $\geq 5.0 \mathrm{ng} / \mathrm{ml})$, duration between surgery and C-ion RT $(<27$ or $\geq 27$ months), and surgical indication (not indicated or refused) in OS and LC using the log-rank test.

\section{Results}

Patient characteristics. The clinical characteristics of the 19 patients are summarized in Table I. The median follow-up duration after the initiation of C-ion RT was 19 months (range $=4-55$ months). The median age at the time of registration for C-ion RT was 65 years (range $=47-86$ years). Four patients had two metastatic tumors that received $\mathrm{C}$-ion RT. The number of oligometastatic tumors in the liver and lung was 14 in 11 patients and nine in eight patients, respectively. The median tumor size of 23 lesions was $2.6 \mathrm{~cm}$ (range $=1.1-6.5 \mathrm{~cm}$ ) in maximum diameter, in two cases larger than $5 \mathrm{~cm}$. At the time of $\mathrm{C}$-ion $\mathrm{RT}$, six patients had chemoresistant disease or were unable to continue chemotherapy due to toxicities; 11 patients were unsuitable due to comorbidity and age, or refused chemotherapy. In patients who received chemotherapy before C-ion RT, the median duration from the initiation of chemotherapy for oligometastatic disease to the initiation of C-ion RT was 10 months (range=5-28 months). All patients with liver metastases had Child-Pugh class A and had no liver cirrhosis, and no patients with lung metastases had chronic lung disease or interstitial pneumonia. The dose-fractionation schedules for liver metastases were as follows: Nine lesions received $60 \mathrm{~Gy}$ (RBE) in four fractions, one lesion received $60 \mathrm{~Gy}(\mathrm{RBE})$ in 12 fractions, and four lesions received 64.8 Gy (RBE) in 12 fractions. For lung metastases, there were nine lesions, which 


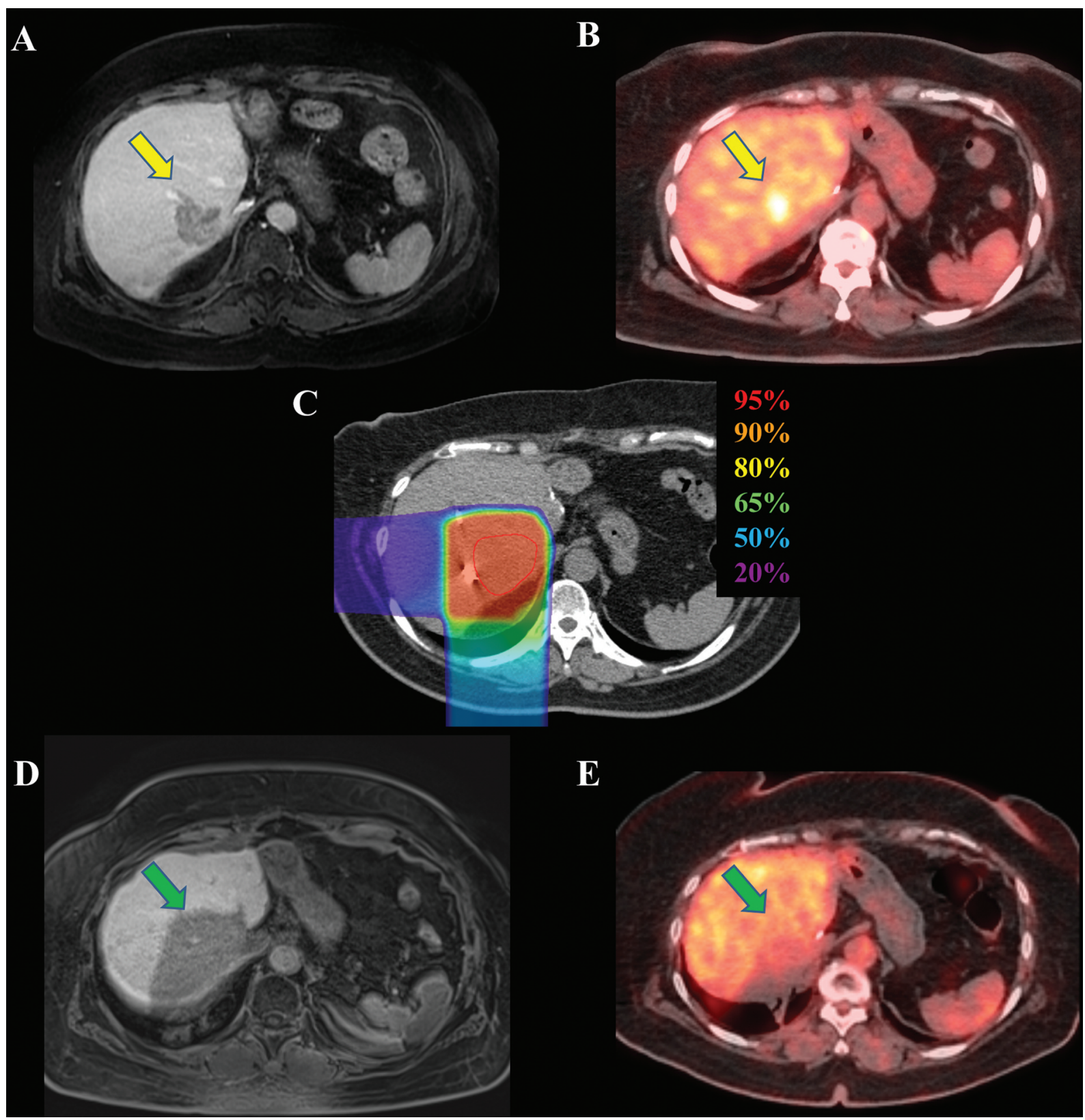

Figure 1. A 65-year-old female with oligometastic sigmoid colon cancer in the liver treated with carbon-ion radiotherapy. A: Contrast-enhanced magnetic resonance imaging in hepatocyte phase before treatment. Yellow arrow shows the tumor with tumor washout. B: 2-Deoxy-2-[18F]fluoro$D$-glucose (FDG) positron-emission tomography before treatment. Yellow arrow shows the tumor with abnormal FDG uptake. C: Dose distribution on axial computed tomographic images. The area within the red outline is the gross tumor volume. The 95\% (red), 90\% (orange), 80\% (yellow), $65 \%$ (green), $50 \%$ (blue), and 20\% (purple) isodose curves are highlighted (100\% was 60 Gy relative biological effectiveness). D: Contrast-enhanced magnetic resonance imaging in hepatic phase 3 months after treatment. Contrast-enhanced deterioration is observed at the site of the carbon-ion beam path and no recurrence or residual tumor evident (green arrow). E: FDG positron-emission tomography 12 months after treatment. FDG uptake was reduced compared to that before treatment (green arrow).

received $60 \mathrm{~Gy}(\mathrm{RBE})$ in four fractions. Three patients did not achieve dose coverage of the $95 \%$ PTV with at least $95 \%$ of the prescribed dose as priority was given to the dose constraint of normal organs such as the gastrointestinal tract or skin.
Clinical outcomes. Figures 1D and 1E, and 2D and 2E show typical radiographic images after C-ion RT. The estimated 2year OS, LC, and PFS rates for the cohort overall were $100 \%, 67 \%$, and $35 \%$, respectively; for those with liver 


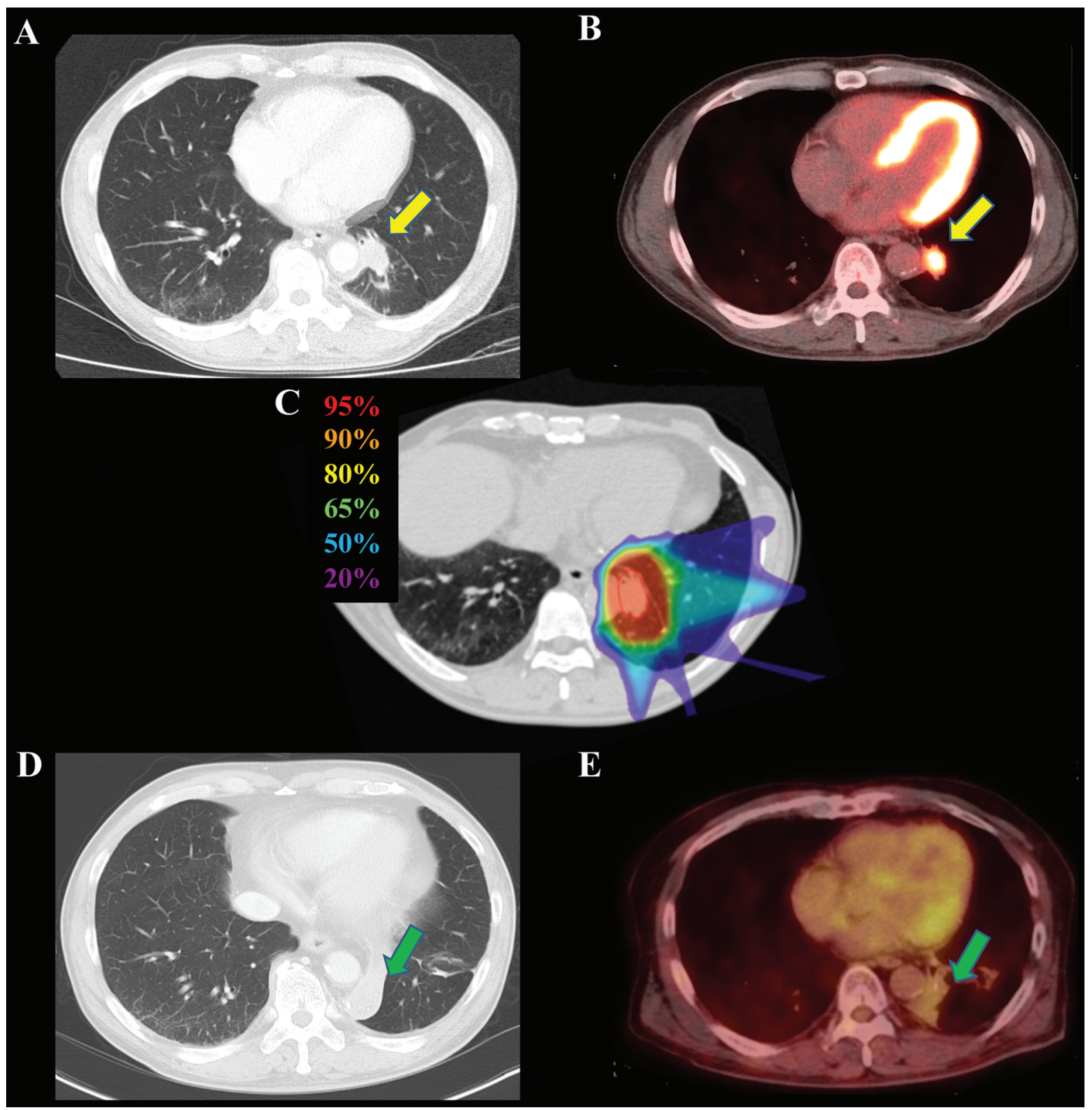

Figure 2. A 58-year-old male with oligometastic colorectal cancer in lung treated with carbon-ion radiotherapy. A: Plain computed tomography (CT) before treatment. Yellow arrow shows the tumor with contrast enhancement. B: 2-Deoxy-2- ${ }^{18}$ F]fluoro-D-glucose (FDG) positron-emission tomography before treatment. Yellow arrow shows the tumor with abnormal FDG uptake. C: Dose distribution on axial CT images. The area within the red outline is the gross tumor volume. The 95\% (red), 90\% (orange), 80\% (yellow), 65\% (green), 50\% (blue), and 20\% (purple) isodose curves are highlighted [100\% was 60 Gy (relative biological effectiveness)]. D: Plain CT 12 months after treatment. No recurrence or residual tumor evident (green arrow). E: FDG positron-emission tomography 12 months after treatment. FDG uptake was reduced compared to that before treatment (green arrow).

metastases, the corresponding rates were $100 \%, 61 \%$, and $27 \%$; and for those with lung metastases, the rates were $100 \%, 83 \%$, and $48 \%$, respectively (Figure 3 ).

Four out of 14 lesions (29\%) in the liver and one out of nine lesions $(11 \%)$ in the lung developed local recurrence after C-ion RT. Two locally recurrent lesions in the liver received $64.8 \mathrm{~Gy}(\mathrm{RBE})$ in 12 fractions, and the other two received 60.0 Gy $(\mathrm{RBE})$ in four fractions. A local recurrence in the lung received 60.0 Gy (RBE) in four fractions. All local recurrences were central tumor recurrences. All patients 
Table I. Patient characteristics.

\begin{tabular}{|c|c|c|c|c|}
\hline Characteristic & & All & Liver metastases & Lung metastases \\
\hline Total & Number & 19 & 11 & 8 \\
\hline Age, years & Median (range) & $65(47-86)$ & $65(47-76)$ & $73(58-86)$ \\
\hline \multirow[t]{2}{*}{ Gender, $\mathrm{n}$} & Male & 14 & 8 & 6 \\
\hline & Female & 5 & 3 & 2 \\
\hline \multirow[t]{2}{*}{ Performance status, $\mathrm{n}$} & 0 & 9 & 5 & 4 \\
\hline & 1 & 10 & 6 & 4 \\
\hline \multirow[t]{2}{*}{ Primary tumor site, $\mathrm{n}$} & Colon & 11 & 5 & 6 \\
\hline & Rectum & 8 & 6 & 2 \\
\hline \multirow{2}{*}{ Tumor number, $\mathrm{n}$} & 1 & 15 & 8 & 7 \\
\hline & 2 & 4 & 3 & 1 \\
\hline Surgery for primary disease to C-ion RT, months & Median (range) & $27(4-159)$ & $24(6-38)$ & $36(4-159)$ \\
\hline \multirow[t]{2}{*}{ Chemotherapy before $\mathrm{C}$-ion RT } & Presence & 8 & 8 & 0 \\
\hline & Absence & 11 & 3 & 8 \\
\hline \multirow[t]{2}{*}{ Adjuvant treatment of $\mathrm{C}$-ion $\mathrm{RT}$} & Presence & 2 & 1 & 1 \\
\hline & Absence & 17 & 10 & 7 \\
\hline \multirow[t]{2}{*}{ Surgical indication } & Not indicated & 9 & 5 & 4 \\
\hline & Refused & 10 & 6 & 4 \\
\hline Serum CEA level before C-ion RT, $\mathrm{ng} / \mathrm{ml}$ & Median (range) & $4.1(1.6-3,677.0)$ & $8.4(1.6-3,677.0)$ & $3.2(1.4-10.9)$ \\
\hline Tumor size, $\mathrm{cm}$ & Median (range) & $2.6(1.1-6.5)$ & $3.1(1.5-6.5)$ & $2.1(1.1-3.2)$ \\
\hline GTV volume, $\mathrm{cm}^{3}$ & Median (range) & $8.4(0.6-113.7)$ & $24.7(2.9-113.7)$ & $2.8(0.6-23.2)$ \\
\hline CTV volume, $\mathrm{cm}^{3}$ & Median (range) & $42.0(5.8-248.2)$ & $112.8(29.0-248.2)$ & $13.5(5.8-53.1)$ \\
\hline
\end{tabular}

CEA: Carcinoembryonic antigen; C-ion RT: carbon ion radiotherapy; CTV volume: clinical target volume; GTV: gross tumor volume; RBE: relative biological effectiveness.

with local recurrence also developed distant or lymph node metastases. Twelve patients developed distant or lymph node metastases. Three patients died of colorectal cancer.

The observed cases of acute and late toxicities are shown in Table II. None of the patients developed grade 2 or higher acute and late toxicities. No patients developed radiationinduced liver disease (RILD) or Child-Pugh class decline. Table III lists DVH parameters. Analysis did not reveal any significant prognostic factors for OS and LC (Table IV).

\section{Discussion}

Surgery for oligometastatic colorectal cancer in the liver and lung is well established, and previous studies have reported 5 -year survival of $30-61 \%(2-7)$. These results suggest that local treatment for oligometastatic colorectal cancer improves survival. Another local treatment approach is SBRT, which is indicated for patients who are unsuitable for surgery or refuse surgery. Previous reports of SBRT for oligometastatic colorectal cancer showed that the 2-year OS and LC were $57-75 \%$ and $36-91 \%$, respectively, for patients with liver metastases and $68-89 \%$ and $58-80 \%$, respectively, for those with lung metastases, with grade 3-4 toxicities developing in $0-9 \%$ of patients (8-15). These results suggest that SBRT is an effective local treatment approach and might improve OS in oligometastatic colorectal cancer. In our study, C-ion RT was performed in patients with oligometastatic colorectal cancer who were unsuitable for surgery or refused surgery. The OS and LC rates were $100 \%$ and $61 \%$, respectively, for those with liver metastases, and $100 \%$ and $83 \%$, respectively, for those with lung metastases, with no grade 2 or higher toxicities. These outcomes are comparable to those in previous reports of SBRT. Additionally, we included patients with inoperable disease and those difficult to treat with chemotherapy; hence, local treatment with $\mathrm{C}$-ion RT might improve OS, underscoring the value of $\mathrm{C}$-ion $\mathrm{RT}$.

We performed DVH analysis for the normal liver. A previous report investigating the relationship between normal liver DVH parameters and liver function after photon therapy found that a mean liver dose $>23 \mathrm{~Gy}, \mathrm{~V}_{5}>86 \%, \mathrm{~V}_{10}>68 \%$, $\mathrm{V}_{15}>59 \%, \mathrm{~V}_{20}>49 \%, \mathrm{~V}_{25}>35 \%, \mathrm{~V}_{30}>28 \%$, and $\mathrm{V} 40$ $>20 \%$ were risk factors of RILD (28). Another study on SBRT showed that $\mathrm{V}_{25}>32 \%$ was a risk factor for ChildPugh class decline in patients with hepatocellular carcinoma (29). In the present study, $\mathrm{V}_{25}-\mathrm{V}_{40} \mathrm{DVH}$ parameters of liver were exceeded in a few patients with multiple or tumors of $3 \mathrm{~cm}$ or larger. However, none of the patients developed RILD and Child-Pugh class decline. In previous studies, a risk factor of RILD and Child-Pugh class decline was liver cirrhosis in patients with hepatocellular carcinoma. However, we did not include patients with liver cirrhosis in our cohort, 

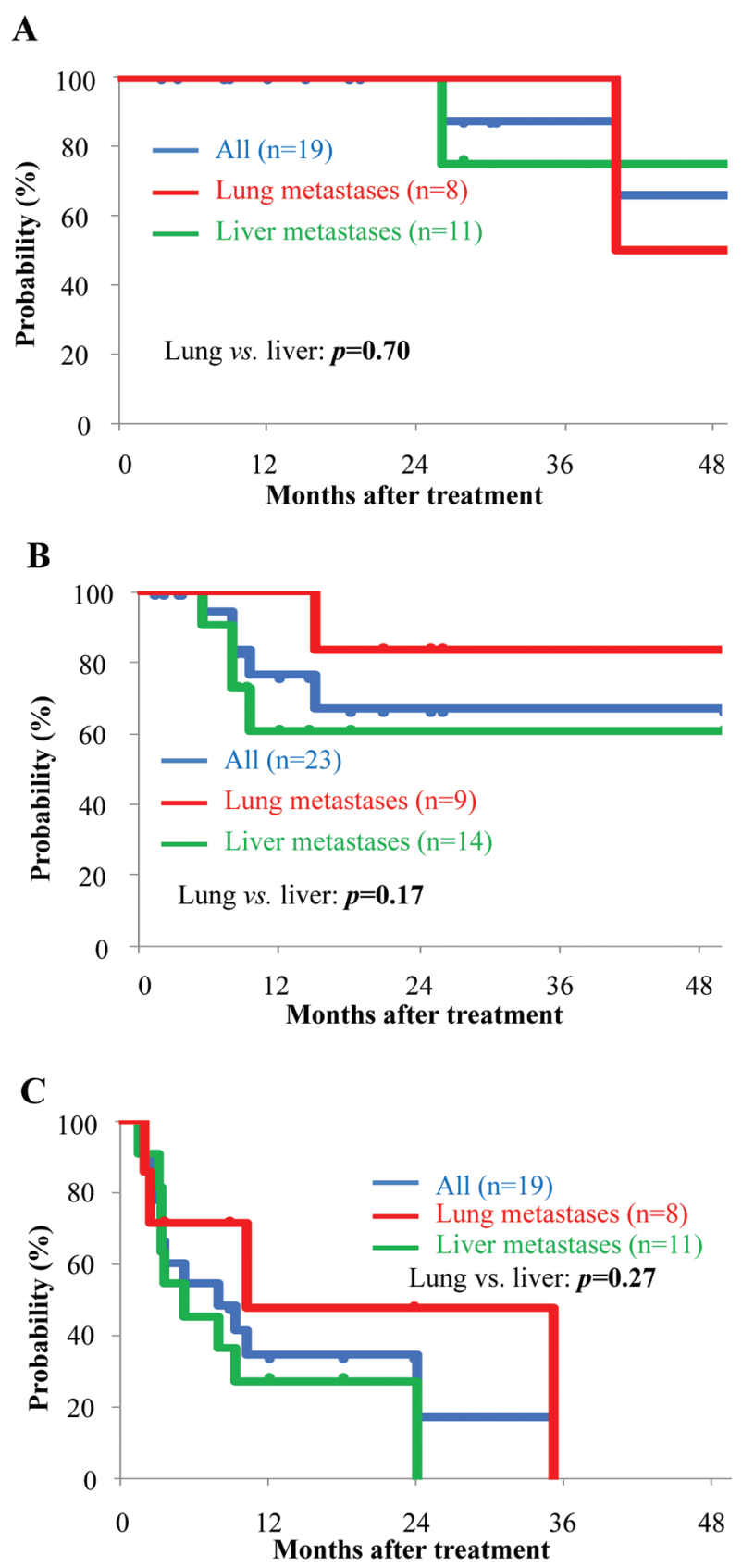

Figure 3. Kaplan-Meier curves of overall survival (OS) (A), local control $(L C)(B)$ and progression-free survival $(C)$ for the whole patient cohort, patients with liver metastases, and those with lung metastases.

which explains the absence of RILD and Child-Pugh class decline in our study. The DVH analysis for normal lung in previous studies showed that risk factors for grade 2 or higher radiation-induced pneumonitis were a mean lung dose of $>5$ Gy and $\mathrm{V}_{20}>7 \%$ in those treated with SBRT and $\mathrm{V}_{30}$ $>15 \%$ in C-ion those treated with RT $(30,31)$. In the present
Table II. Acute and late toxicities according to Common Terminology Criteria for Adverse Events, version 4.0 (27) (N=19).

\begin{tabular}{lllllll}
\hline & \multicolumn{5}{c}{ Grade, $\mathrm{n}$} \\
\cline { 3 - 7 } & & 0 & 1 & 2 & 3 & 4 \\
\hline \multirow{2}{*}{ Toxicite } & Dermatitis & 13 & 6 & 0 & 0 & 0 \\
& GI tract & 19 & 0 & 0 & 0 & 0 \\
& Pneumonitis & 18 & 1 & 0 & 0 & 0 \\
& Pleural effusion/ascites & 19 & 0 & 0 & 0 & 0 \\
Late & 19 & 0 & 0 & 0 & 0 \\
Hepatobiliary & 17 & 2 & 0 & 0 & 0 \\
Dermatitis & 19 & 0 & 0 & 0 & 0 \\
& GI tract & 13 & 6 & 0 & 0 & 0 \\
& Pneumonitis & 19 & 0 & 0 & 0 & 0 \\
& Pleural effusion/ascites & 19 & 0 & 0 & 0 & 0 \\
Hepatobiliary & 19 & 0 & 0 & 0 & 0 \\
Bone fracture & & & & &
\end{tabular}

GI: Gastrointestinal.

study, $\mathrm{V}_{30}$ did not exceeded $15 \%$ in any of the patients, and in only a few patients with multiple or large tumors $(\geq 3 \mathrm{~cm})$ did the mean Iung dose exceed $>5$ Gy and $\mathrm{V}_{20}$ exceed $7 \%$. However, none of the patients developed grade 2 or higher radiation-induced pneumonitis. These clinical results and DVH parameters suggest that the use of C-ion RT for oligometastatic colorectal cancer in patients with single 3$\mathrm{cm}$ or smaller tumors in liver and lung is a safe treatment approach, and in those with multiple tumors or $3 \mathrm{~cm}$ or larger tumor might be safe considering the liver or lung background.

The improvement of LC might trigger more interest in Cion RT for oligometastatic colorectal cancer. In a previous report of C-ion RT for oligometastatic colorectal cancer in the liver, 3-year LC rates were $82 \%$ in those receiving single-fraction doses of $53 \mathrm{~Gy}$ (RBE) or higher and $28 \%$ in those receiving 48 Gy (RBE) or lower $(p=0.01)$ (21). Additionally, 3-year LC was 86-93\% after the administration of 70 Gy (RBE) in 16 fractions or higher in patients with pelvic recurrence of colorectal cancer $(32,33)$. In the present study, all cases with local recurrence had central recurrence after administration of $60 \mathrm{~Gy}$ (RBE) in four fractions or 64.8 Gy (RBE) in 12 fractions. These results suggest a dose deficiency with the prescribed dose in our study. Higher dose irradiation such as $53 \mathrm{~Gy}$ (RBE) in a single fraction or 70 Gy (RBE) in 16 fractions without exceeding the tolerable dose with DVH in normal liver or lung might improve LC. In the present study, we considered that increasing the prescribed dose might be safe for small and single tumors.

Research on particle therapy, including proton beam therapy and C-ion RT, for oligometastatic colorectal cancer in the liver or lung is limited $(21,34,35)$. All reports showed favorable and similar results to those using SBRT. Our 
Table III. Dose-volume histogram parameters.

\begin{tabular}{|c|c|c|c|c|}
\hline \multirow[t]{2}{*}{ Organ } & \multirow[b]{2}{*}{ Parameter } & \multicolumn{3}{|c|}{ Median (range) } \\
\hline & & All $(\mathrm{N}=11)$ & $\begin{array}{l}\text { Single and small tumor } \\
\qquad(<3 \mathrm{~cm})(\mathrm{N}=6)\end{array}$ & $\begin{array}{l}\text { Multiple or large tumor } \\
\qquad(\geq 3 \mathrm{~cm})(\mathrm{N}=5)\end{array}$ \\
\hline \multirow[t]{9}{*}{ Liver } & Mean dose, Gy & $13.9(5.2-26.3)$ & $7.0(5.2-17.2)$ & $21.2(13.9-26.4)$ \\
\hline & $\mathrm{V}_{5}$ & $35 \%(12-69 \%)$ & $21 \%(12-37 \%)$ & $61 \%(35-69 \%)$ \\
\hline & $\mathrm{V}_{10}$ & $32 \%(10-51 \%)$ & $18 \%(10-33 \%)$ & $47 \%(32-51 \%)$ \\
\hline & $\mathrm{V}_{15}$ & $30 \%(9-47 \%)$ & $17 \%(9-32 \%)$ & $41 \%(30-47 \%)$ \\
\hline & $\mathrm{V}_{20}$ & $28 \%(8-45 \%)$ & $11 \%(8-31 \%)$ & $39 \%(28-45 \%)$ \\
\hline & $\mathrm{V}_{25}$ & $25 \%(6-41 \%)$ & $10 \%(6-29 \%)$ & $37 \%(25-41 \%)$ \\
\hline & $\mathrm{V}_{30}$ & $21 \%(5-40 \%)$ & $9 \%(5-27 \%)$ & $34 \%(21-40 \%)$ \\
\hline & $\mathrm{V}_{40}$ & $16 \%(5-36 \%)$ & $8 \%(5-23 \%)$ & $27 \%(16-36 \%)$ \\
\hline & $\mathrm{V}_{50}$ & $13 \%(4-33 \%)$ & $7 \%(4-21 \%)$ & $23 \%(13-33 \%)$ \\
\hline \multirow[t]{9}{*}{ Lung } & Mean dose, Gy & $3.1(1.7-7.3)$ & $1.9(1.7-2.8)$ & $5.3(3.4-7.3)$ \\
\hline & $\mathrm{V}_{5}$ & $12 \%(6-23 \%)$ & $7 \%(6-10 \%)$ & $18 \%(14-23 \%)$ \\
\hline & $\mathrm{V}_{10}$ & $10 \%(4-19 \%)$ & $5 \%(4-8 \%)$ & $16 \%(12-19 \%)$ \\
\hline & $\mathrm{V}_{15}$ & $8 \%(4-17 \%)$ & $4 \%(4-7 \%)$ & $13 \%(9-17 \%)$ \\
\hline & $\mathrm{v}_{20}$ & $6 \%(3-14 \%)$ & $3 \%(3-5 \%)$ & $11 \%(6-14 \%)$ \\
\hline & $\mathrm{V}_{25}$ & $5 \%(3-13 \%)$ & $3 \%(3-5 \%)$ & $8 \%(5-13 \%)$ \\
\hline & $\mathrm{V}_{30}$ & $4 \%(2-11 \%)$ & $2 \%(2-4 \%)$ & $7 \%(4-11 \%)$ \\
\hline & $\mathrm{V}_{40}^{30}$ & $2 \%(1-8 \%)$ & $2 \%(1-2 \%)$ & $4 \%(2-8 \%)$ \\
\hline & $\mathrm{V}_{50}$ & $2 \%(1-6 \%)$ & $1 \%(1-2 \%)$ & $3 \%(2-6 \%)$ \\
\hline
\end{tabular}

$\mathrm{V}_{5}-\mathrm{V}_{50}$ : The percentage of the liver or lung volume that received at least 5-50 Gy (relative biological effectiveness).

Table IV. Univariate analysis of overall survival (OS) and local control (LC).

\begin{tabular}{|c|c|c|c|c|c|}
\hline \multirow[b]{2}{*}{ Factor } & & \multicolumn{2}{|c|}{ OS } & \multicolumn{2}{|c|}{$\mathrm{LC}$} \\
\hline & & 2-Year OS & $p$-Value & 2-Year LC & $p$-Value \\
\hline Gender & Male vs. female & $100 \%$ vs. $100 \%$ & 0.34 & $51 \%$ vs. $100 \%$ & 0.10 \\
\hline Age & $<65$ vs. $\geq 65$ years & $100 \%$ vs. $100 \%$ & 0.96 & $57 \%$ vs. $73 \%$ & 0.36 \\
\hline PS & 0 vs. 1 & $100 \%$ vs. $100 \%$ & 0.43 & $60 \%$ vs. $80 \%$ & 0.63 \\
\hline Primary tumor site & Rectum $v s$. colon & $100 \%$ vs. $100 \%$ & 0.52 & $64 \%$ vs. $75 \%$ & 0.62 \\
\hline Tumor location & Liver vs. lung & $100 \%$ vs. $100 \%$ & 0.70 & $61 \%$ vs. $83 \%$ & 0.17 \\
\hline Tumor number & 1 vs. 2 & $100 \%$ vs. $100 \%$ & 0.25 & $67 \%$ vs. $67 \%$ & 0.57 \\
\hline Surgery for primary disease to C-ion RT & $<27$ vs. $\geq 27$ months & $100 \%$ vs. $100 \%$ & 0.52 & $56 \%$ vs. $75 \%$ & 0.33 \\
\hline Surgical indication & Not indicated $v s$. refused & $100 \%$ vs. $100 \%$ & 0.80 & $67 \%$ vs. $66 \%$ & 0.51 \\
\hline CEA & $<5.0 v s . \geq 5.0 \mathrm{ng} / \mathrm{ml}$ & $100 \%$ vs. $100 \%$ & 0.07 & $88 \%$ vs. $43 \%$ & 0.05 \\
\hline Tumor size & $<3$ vs. $\geq 3 \mathrm{~cm}$ & $100 \%$ vs. $100 \%$ & 0.23 & $69 \%$ vs. $63 \%$ & 0.39 \\
\hline GTV & $<10 \mathrm{vs} . \geq 10 \mathrm{~cm}^{3}$ & $100 \%$ vs. $100 \%$ & 0.18 & $70 \%$ vs. $57 \%$ & 0.26 \\
\hline CTV & $<40 v s . \geq 40 \mathrm{~cm}^{3}$ & $100 \%$ vs. $100 \%$ & 0.35 & $80 \%$ vs. $56 \%$ & 0.13 \\
\hline
\end{tabular}

CEA: Carcinoembryonic antigen; C-ion RT: carbon-ion radiotherapy; CTV: clinical target volume; GTV: gross tumor volume; PS: performance status.

findings are also favorable and comparable to the SBRT results and previous particle therapy.

Our study had several limitations. Firstly, this was a single-institutional retrospective analysis with a small number of patients and a short follow-up duration. Secondly, the patient backgrounds were heterogeneous. Thirdly, analyses of DVH and toxicities for C-ion RT were few, and the threshold risk value in the incidence of toxicities is unknown. Despite these limitations, this study confirmed the safety of C-ion RT. Our study offers useful information on the treatment of oligometastatic colorectal cancer, especially in patients who are unsuitable for surgery.

In conclusion, $\mathrm{C}$-ion RT is a favorable treatment approach for oligometastatic colorectal cancer in the liver and lungs 
and has comparable clinical outcomes to SBRT. Additionally, C-ion RT might be a safe treatment option, as exemplified by the absence of RILD and radiation-induced pneumonitis. Therefore, C-ion RT can be used in patients with oligometastatic colorectal cancer in the liver and lungs who are unsuitable for surgery.

\section{Conflicts of Interest}

The Authors declare no conflicts of interest in regard to this study.

\section{Authors' Contributions}

Conceptualization, S.S., T.O.; methodology, S.S., K.S., O.M., H.K., T.O; validation, S.S.; formal analysis, S.S.; investigation, S.S., K.S., M.O., H.K.; resources, S.S., K.S., M.O., H.K.; data curation, S.S.; writing-original draft preparation, S.S.; writing-review and editing, K.S., M.O., N.O., N.K., T.K., H.S., S.O., Y.M., H.K., T.O.; visualization, S.S.; supervision, T.O.; project administration, T.O.; funding acquisition, T.O. All Authors read and approved the final article.

\section{Acknowledgements}

The Authors would like to thank all the patients who were involved in this study, our colleagues at Gunma University Heavy Ion Medical Center and Department of Radiation Oncology Gunma University Graduate School of Medicine, and Editage (www.editage.com) for English language editing.

\section{References}

1 Hellman S and Weichselbaum RR: Oligometastases. J Clin Oncol 13(1): 8-10, 1995. PMID: 7799047. DOI: 10.1200/JCO.1995.13.1.8

2 Rees M, Tekkis PP, Welsh FK, O'Rourke T and John TG: Evaluation of long-term survival after hepatic resection for metastatic colorectal cancer: A multifactorial model of 929 patients. Ann Surg 247(1): 125-135, 2008. PMID: 18156932. DOI: $10.1097 /$ SLA.0b013e31815aa2c2

3 Elias D, Liberale G, Vernerey D, Pocard M, Ducreux M, Boige V, Malka D, Pignon JP and Lasser P: Hepatic and extrahepatic colorectal metastases: When resectable, their localization does not matter, but their total number has a prognostic effect. Ann Surg Oncol 12(11): 900-909, 2005. PMID: 16184442. DOI: 10.1245/ASO.2005.01.010

4 Inoue $\mathrm{M}$, Ohta $\mathrm{M}$, Iuchi $\mathrm{K}$, Matsumura A, Ideguchi $\mathrm{K}$, Yasumitsu T, Nakagawa K, Fukuhara K, Maeda H, Takeda S, Minami M, Ohno Y, Matsuda H and Thoracic Surgery Study Group of Osaka University.: Benefits of surgery for patients with pulmonary metastases from colorectal carcinoma. Ann Thorac Surg 78(1): 238-244, 2004. PMID: 15223436. DOI: 10.1016/ j.athoracsur.2004.02.017

5 Pfannschmidt J, Dienemann H and Hoffmann H: Surgical resection of pulmonary metastases from colorectal cancer: A systematic review of published series. Ann Thorac Surg 84(1): 324-338, 2007. PMID: 17588454. DOI: 10.1016/j.athoracsur.2007.02.093

6 Kopetz S, Chang GJ, Overman MJ, Eng C, Sargent DJ, Larson DW, Grothey A, Vauthey JN, Nagorney DM and McWilliams
RR: Improved survival in metastatic colorectal cancer is associated with adoption of hepatic resection and improved chemotherapy. J Clin Oncol 27(22): 3677-3683, 2009. PMID: 19470929. DOI: $10.1200 / J C O .2008 .20 .5278$

7 Salah S, Watanabe K, Welter S, Park JS, Park JW, Zabaleta J, Ardissone F, Kim J, Riquet M, Nojiri K, Gisabella M, Kim SY, Tanaka K and Al-Haj Ali B: Colorectal cancer pulmonary oligometastases: Pooled analysis and construction of a clinical lung metastasectomy prognostic model. Ann Oncol 23(10): 26492655, 2012. PMID: 22547539. DOI: 10.1093/annonc/mds 100

8 Petrelli F, Comito T, Barni S, Pancera G, Scorsetti M, Ghidini A and SBRT for CRC liver metastases.: Stereotactic body radiotherapy for colorectal cancer liver metastases: A systematic review. Radiother Oncol 129(3): 427-434, 2018. PMID: 29997034. DOI: 10.1016/j.radonc.2018.06.035

9 Comito T, Cozzi L, Clerici E, Campisi MC, Liardo RL, Navarria P, Ascolese A, Tozzi A, Iftode C, De Rose F, Villa E, Personeni N, Rimassa L, Santoro A, Fogliata A, Mancosu P, Tomatis S and Scorsetti M: Stereotactic Ablative Radiotherapy (SABR) in inoperable oligometastatic disease from colorectal cancer: A safe and effective approach. BMC Cancer 14: 619, 2014. PMID: 25163798. DOI: $10.1186 / 1471-2407-14-619$

10 Habermehl D, Herfarth KK, Bermejo JL, Hof H, Rieken S, Kuhn S, Welzel T, Debus J and Combs SE: Single-dose radiosurgical treatment for hepatic metastases - therapeutic outcome of 138 treated lesions from a single institution. Radiat Oncol 8: 175, 2013. PMID: 23837905. DOI: 10.1186/1748-717X-8-175

11 Joo JH, Park JH, Kim JC, Yu CS, Lim SB, Park IJ, Kim TW, Hong YS, Kim KP, Yoon SM, Park J and Kim JH: Local control outcomes using stereotactic body radiation therapy for liver metastases from colorectal cancer. Int J Radiat Oncol Biol Phys 99(4): 876-883, 2017. PMID: 29063852. DOI: 10.1016/j.ijrobp. 2017.07.030

12 Jingu K, Matsushita H, Yamamoto T, Umezawa R, Ishikawa Y, Takahashi N, Katagiri Y, Takeda K and Kadoya N: Stereotactic radiotherapy for pulmonary oligometastases from colorectal cancer: A systematic review and meta-analysis. Technol Cancer Res Treat 17: 1533033818794936, 2018. PMID: 30145943. DOI: $10.1177 / 1533033818794936$

13 Agolli L, Bracci S, Nicosia L, Valeriani M, De Sanctis V and Osti MF: Lung metastases treated with stereotactic ablative radiation therapy in oligometastatic colorectal cancer patients: Outcomes and prognostic factors after long-term follow-up. Clin Colorectal Cancer 16(1): 58-64, 2017. PMID: 27522627. DOI: 10.1016/j.clcc.2016.07.004

14 Kinj R, Bondiau PY, François E, Gérard JP, Naghavi AO, Leysalle A, Chamorey E, Evesque L, Padovani B, Ianessi A, Benezery K and Doyen J: Radiosensitivity of colon and rectal lung oligometastasis treated with stereotactic ablative radiotherapy. Clin Colorectal Cancer 16(3): e211-e220, 2017. PMID: 27670890. DOI: 10.1016/j.clcc.2016.08.003

15 Kobayashi N, Abe T, Noda SE, Kumazaki YU, Hirai R, Igari M, Aoshika T, Saito S, Ryuno Y and Kato S: Stereotactic body radiotherapy for pulmonary oligometastasis from colorectal cancer. In Vivo 34(5): 2991-2996, 2020. PMID: 32871842. DOI: 10.21873 /invivo. 12130

16 Shibuya K, Ohno T, Terashima K, Toyama S, Yasuda S, Tsuji H, Okimoto T, Shioyama Y, Nemoto K, Kamada T, Nakano T and Japan Carbon Ion Radiotherapy Study Group.: Short-course carbon-ion radiotherapy for hepatocellular carcinoma: A multi- 
institutional retrospective study. Liver Int 38(12): 2239-2247, 2018. PMID: 30240527. DOI: 10.1111/liv.13969

17 Shiba S, Shibuya K, Okamoto M, Okazaki S, Komatsu S, Kubota $\mathrm{Y}$, Nakano $\mathrm{T}$ and Ohno $\mathrm{T}$ : Clinical impact of hypofractionated carbon ion radiotherapy on locally advanced hepatocellular carcinoma. Radiat Oncol 15(1): 195, 2020. PMID: 32795340. DOI: 10.1186/s13014-020-01634-z

18 Saitoh JI, Shirai K, Mizukami T, Abe T, Ebara T, Ohno T, Minato K, Saito R, Yamada M and Nakano T: Hypofractionated carbonion radiotherapy for stage I peripheral nonsmall cell lung cancer (GUNMA0701): Prospective phase II study. Cancer Med 8(15): 6644-6650, 2019. PMID: 31532584. DOI: 10.1002/cam4.2561

19 Okonogi N, Kaminuma T, Okimoto T, Shinoto M, Yamamoto N, Yamada S, Murata K, Ohno T, Shioyama Y, Tsuji H, Nakano T and Kamada T: Carbon-ion radiotherapy for lymph node oligorecurrence: a multi-institutional study by the Japan Carbon-Ion Radiation Oncology Study Group (J-CROS). Int J Clin Oncol 24(9): 1143-1150, 2019. PMID: 30968270. DOI: 10.1007/s10147019-01440-y

20 Shiba S, Okonogi N, Kato S, Wakatsuki M, Kobayashi D, Kiyohara H, Ohno T, Karasawa K, Nakano T and Kamada T: Clinical impact of re-irradiation with carbon-ion radiotherapy for lymph node recurrence of gynecological cancers. Anticancer Res 37(10): 5577-5583, 2017. PMID: 28982873. DOI: 10.21873/ anticanres.11991

21 Makishima H, Yasuda S, Isozaki Y, Kasuya G, Okada N, Miyazaki M, Mohamad O, Matsufuji N, Yamada S, Tsuji H, Kamada T and Liver Cancer Working Group.: Single fraction carbon ion radiotherapy for colorectal cancer liver metastasis: A dose escalation study. Cancer Sci 110(1): 303-309, 2019. PMID: 30417485. DOI: $10.1111 /$ cas.13872

22 Kanai T, Endo M, Minohara S, Miyahara N, Koyama-ito H, Tomura H, Matsufuji N, Futami Y, Fukumura A, Hiraoka T, Furusawa Y, Ando K, Suzuki M, Soga F and Kawachi K: Biophysical characteristics of HIMAC clinical irradiation system for heavy-ion radiation therapy. Int J Radiat Oncol Biol Phys 44(1): 201-210, 1999. PMID: 10219815. DOI: 10.1016/s03603016(98)00544-6

23 Abe T, Saitoh J, Kobayashi D, Shibuya K, Koyama Y, Shimada H, Shirai K, Ohno T and Nakano T: Dosimetric comparison of carbon ion radiotherapy and stereotactic body radiotherapy with photon beams for the treatment of hepatocellular carcinoma. Radiat Oncol 10: 187, 2015. PMID: 26377092. DOI: 10.1186/s13014-015-0491-8

24 Shiba S, Shibuya K, Kawashima M, Okano N, Kaminuma T, Okamoto M, Kubota Y, Nakano T and Ohno T: Comparison of dose distributions when using carbon ion radiotherapy versus intensity-modulated radiotherapy for hepatocellular carcinoma with macroscopic vascular invasion: A retrospective analysis. Anticancer Res 40(1): 459-464, 2020. PMID: 31892601. DOI: 10.21873/anticanres.13974

25 Ebara T, Shimada H, Kawamura H, Shirai K, Saito J, Kawashima M, Tashiro M, Ohno T, Kanai T and Nakano T: Dosimetric analysis between carbon ion radiotherapy and stereotactic body radiotherapy in stage I lung cancer. Anticancer Res 34(9): 5099-5104, 2014. PMID: 25202098.

26 Inaniwa T, Kanematsu N, Matsufuji N, Kanai T, Shirai T, Noda K, Tsuji H, Kamada T and Tsujii H: Reformulation of a clinicaldose system for carbon-ion radiotherapy treatment planning at the National Institute of Radiological Sciences, Japan. Phys Med
Biol 60(8): 3271-3286, 2015. PMID: 25826534. DOI: $10.1088 / 0031-9155 / 60 / 8 / 3271$

27 NCI Common Terminology Criteria for Adverse Events (CTCAE) Version 4.0. National Institutes of Health, National Cancer Institute, Bethesda, MA, USA, 2009. Available at: https://evs.nci.nih.gov/ftp1/CTCAE/CTCAE_4.03/Archive/CTC AE_4.0_2009-05-29_QuickReference_8.5x11.pdf [Last accessed on February 24, 2021]

28 Liang SX, Zhu XD, Xu ZY, Zhu J, Zhao JD, Lu HJ, Yang YL, Chen L, Wang AY, Fu XL and Jiang GL: Radiation-induced liver disease in three-dimensional conformal radiation therapy for primary liver carcinoma: the risk factors and hepatic radiation tolerance. Int J Radiat Oncol Biol Phys 65(2): 426-434, 2006. PMID: 16690430. DOI: 10.1016/j.ijrobp.2005.12.031

29 Dyk P, Weiner A, Badiyan S, Myerson R, Parikh P and Olsen J: Effect of high-dose stereotactic body radiation therapy on liver function in the treatment of primary and metastatic liver malignancies using the Child-Pugh score classification system. Pract Radiat Oncol 5(3): 176-182, 2015. PMID: 25423889. DOI: 10.1016/j.prro.2014.09.007

30 Barriger RB, Forquer JA, Brabham JG, Andolino DL, Shapiro RH, Henderson MA, Johnstone PA and Fakiris AJ: A dosevolume analysis of radiation pneumonitis in non-small cell lung cancer patients treated with stereotactic body radiation therapy. Int J Radiat Oncol Biol Phys 82(1): 457-462, 2012. PMID: 21035956. DOI: 10.1016/j.ijrobp.2010.08.056

31 Hayashi K, Yamamoto N, Karube M, Nakajima M, Matsufuji N, Tsuji H, Ogawa K and Kamada T: Prognostic analysis of radiation pneumonitis: Carbon-ion radiotherapy in patients with locally advanced lung cancer. Radiat Oncol 12(1): 91, 2017. PMID: 28558766. DOI: 10.1186/s13014-017-0830-Z

32 Shiba S, Okamoto M, Kiyohara H, Ohno T, Kaminuma T, Asao T, Ojima H, Shirabe K, Kuwano H and Nakano T: Prospective observational study of high-dose carbon-ion radiotherapy for pelvic recurrence of rectal cancer (GUNMA 0801). Front Oncol 9: 702, 2019. PMID: 31417874. DOI: 10.3389/fonc.2019.00702

33 Shinoto M, Yamada S, Okamoto M, Shioyama Y, Ohno T, Nakano T, Nemoto K, Isozaki Y, Kawashiro S, Tsuji H and Kamada T: Carbon-ion radiotherapy for locally recurrent rectal cancer: Japan Carbon-ion Radiation Oncology Study Group (JCROS) Study 1404 Rectum. Radiother Oncol 132: 236-240, 2019. PMID: 30360998. DOI: 10.1016/j.radonc.2018.10.007

34 Takahashi W, Nakajima M, Yamamoto N, Yamada S, Yamashita $\mathrm{H}$, Nakagawa $\mathrm{K}$, Tsuji $\mathrm{H}$ and Kamada $\mathrm{T}$ : Carbon ion radiotherapy for oligo-recurrent lung metastases from colorectal cancer: a feasibility study. Radiat Oncol 9: 68, 2014. PMID: 24581481. DOI: 10.1186/1748-717X-9-68

35 Fukumitsu N, Okumura T, Takizawa D, Makishima H, Numajiri $\mathrm{H}$, Murofushi K, Ohnishi K, Mizumoto M, Aihara T, Ishikawa $\mathrm{H}$, Tsuboi K and Sakurai H: Proton beam therapy for metastatic liver tumors. Radiother Oncol 117(2): 322-327, 2015. PMID: 26385268. DOI: 10.1016/j.radonc.2015.09.011

Received February 4, 2021

Revised February 24, 2021

Accepted February 25, 2021 